$$
\begin{gathered}
\text { 중국 중학교 교사들의 수행평가에 관한 관심도와 } \\
\text { 실행 수준 분석 } \\
\text { - 북경시 중심으로- } \\
\text { 이서우 · 김태현 · 김석우 } \\
\text { (부산대학교) }
\end{gathered}
$$

\title{
Analysis of Teachers' Concern and Levels of Use on Performance Assessment in China Middle School
}

\author{
Shu-Yu LI $\cdot$ Tae-Hyun KIM $\cdot$ Suk-Woo $\mathrm{KIM}^{\dagger}$ \\ (Pusan National University)
}

\begin{abstract}
The purpose of this study is to analyze middle school teachers' concern about and implementation degree of performance assessment in China. The research questions are as follows: First, what kind of concern is held by middle school teachers who implement performance assessment? Second, is there any significant difference in stages of concern the teachers on performance assessment according to their gender, education level and teaching career? Third, which level of use is shown by middle school teachers who implement performance assessment? Fourth, what is the correlation between middle school teachers' Stages of Concern and Levels of Use on performance assessment? This study was conducted based on a Concerns-Based Adoption Model (Hall, 1973; CBAM) that viewed teachers as the most primary factor of the execution of innovation, in this case, performance assessment. Performance assessment is assessment based on observation and judgement (Stiggins, 1994), and require test takers to complete a process or produce a product in a context that closely resembles real-life situations. The subjects of this study were randomly sampled from 120 middle school teachers throughout Bei-Jing, China. The questionnaires were distributed to them by mail, and they were asked to return their questionnaire by mail. The collect data were analyzed by SPSS/WIN 18.0 program in terms of frequency, correlation, or MANOVA. Frequency analysis was used to analyze concern of middle school teachers on performance assessment. To gain an frequency of the individuals in each stage, we regarded the stage in which a teacher had his/her highest score as his/her relevant stage. Correlation analysis was adopted to identify the correlation between teachers' stage of concern and level of use. To analyze the difference of the concern of China middle school teachers on performance assessment according to their individual background variables such as gender, education level, and teaching career, MANOVA was performed.
\end{abstract}

Key words : Concern, Levels of use, Middle school teachers, Performance assessment

† Corresponding author : 051-510-2628, swkim@pusan.ac.kr 


\section{I. 서 론}

\section{1. 연구의 필요성 및 목적}

21세기는 경제 세계화가 강화되고 그 속에 포 함된 지식 경제의 세계화도 계속 이루어지고 있 는 시대이다. 지금 전 세계 교육은 개혁·개방을 통해 세계화가 이루어지고 있다. 지식 경제화와 경제 세계화가 급속히 이루어지고 있는 가운데 국가 간의 발전 크기가 국민의 자질에 따라 점점 더 달라지고 있다. 교육이 시대에 올바른 인재양 성에 가장 필요한 부분이다. 모든 나라에서 교육 은 국가 발전의 초석이며 각 국가 간 교육에 대 한 입장은 이제 국민의 가장 기본적인 요구사항 으로 되고 있다.

우리나라 대한민국은 1980년대 이후 고도의 눈 부신 경제발전을 이루었다. 별다른 천연자원이 없는 이 땅에서 상당히 많은 발전을 이룰 수 있 었던 것은 인적자원에 대한 많은 투자와 이에 기 초가 되진 교육에 있다고 해도 과언이 아니다.

최근에는 더 많은 국가가 교육부문 개혁을 통 해 국가 발전의 원동력을 이끌어 내고 있다. 지 금 고도의 성장을 거둔 대한민국처럼 전 세계 중 특히 상당한 국가 발전을 모색하고 있는 중국, 이 국가의 눈부신 성장의 원인도 한국과 같은 인 적자원이라 볼 수 있다. 그 인적자원을 길러낸 중국 교육은 꽤 높은 연구가치가 있다고 본다.

현대 사회는 자기주도 학습 능력을 갖춘 인재 의 양성이 요구되어 지고 있다. 이에 따라 교육 뿐만 아니라 이를 위한 적절한 평가체제도 요구 되고 있다. 지금 한국 교육에서는 다양한 평가체 제가 운영되며 중국 교육에서도 역시 다양한 평 가체제가 운영되고 있다. 그러나 중국의 경우 전 반적으로 교육평가체제를 잘 이해하고 관심을 가 지는 교사가 부족하다. 중국의 경우 역시 한국과 마찬가지로 평가체제 중 수행평가 영역이 존재하 며 그에 따른 많은 연구가 이루어지고 있는 중이 다(曲娜, 2009;蔡永红, 2011). 그러나 중국에서 이
루어지고 있는 수행평가의 신뢰성과 타당성에 대 한 연구는 아직 충분하지 않다. 특히 중국 수행 평가 개혁의 주체인 중국 교사가 가지는 수행평 가에 대한 관심도와 수행평가 실행 수준에 대한 연구는 아직 없는 실정이다. 이에 따라 중국 수 행평가의 효율성이 극대화되어 잘 정착할 수 있 는 연구가 필요하다.

본 연구에서는 중국 수행평가 개혁의 주체인 중국 중학교 교사를 상정하고 수행평가에 대한 교사의 관심도와 실행 수준을 분석하고자 한다. 본 연구는 중국 수행평가에 대한 중학교 교사의 관심과 실행수준을 진단하기 위해 Hall 등(1973) 이 개발한 '교사의 관심에 기초한 교육과정 실행 모형 (the Concerns-Based Adoption Model: $\mathrm{CBAM})^{\prime}$ 에 의거하여 수행되었다. 선행연구를 토 대로 살펴보면 $\mathrm{CBAM}$ 가 많은 연구에서 사용되었 으며 잘 고안된 측정도구라는 평가를 받았기 때 문에 본 측정도구를 사용하였다. 이 프로그램을 사용하여 수행에 대한 교사의 관심과 실행 수준 을 진단하고, 그 결과에 근거하여 적절한 지원책 을 제안 받은 많은 연구가 있었기 때문이다. CBAM에 기초한 한국의 국·내외 선행연구들은 다수가 있으며(김은영, 1994; 김재헌, 1997; 박주 상 1993; 장수미, 김재영, 2002; 정미정, 2004; 최 진영, 1996; 曲娜, 2009; 蔡永红, 2011; Darr, 1985; Rutherford, 1977), 이 도구는 지금도 활발한 연 구가 진행되고 있는 검증된 도구이다. 이들 연구 들은 한국의 수행평가에 관한 효과를 검증하는 것이며 나아가 한국의 수행평가에 대한 실태, 평 가, 또는 수행평가에 대한 문제점 등에 대한 연 구이다.

본 연구는 개혁개방 이후 눈부신 성장을 이룬 중국의 교육부분에 초점이 맞추어져 있다. 특히 인 중국의 수도 북경(Beijing)의 교사들을 대상으 로 본 연구는 수행되었다. 이를 통해 본 연구의 목적은 중국 중학교 교사들의 수행평가에 관한 관심도와 실행 수준을 진단하고 이에 따라 현재 중국의 수행평가 현장적용에 대한 문제점을 개선 
할 실질적이고 효과적 방안을 마련하기 위한 기 초자료를 제공하는 데 있다.

\section{II. 이론적 배경}

\section{1. 수행평가}

가. 한국에서의 수행평가

본 연구에서 수행평가란 학생 스스로가 자신의 지식이나 기능을 나타낼 수 있도록 산출물을 만 들거나 행동으로 나타내거나 답을 구성하도록 요 구하는 평가방식이다. 한국의 경우, 이에 대한 국 내·외 수행평가 관련 효과를 검증하거나 평가에 대한 실태, 평가, 또는 평가에 대한 문제점에 대 한 연구가 많이 이루어지고 있다. 그 중 하나, 현 재까지 수행평가에 관한 연구를 살펴보면 수행평 가에 대한 올바른 이해를 공유시키지 못한 채 교 육현장에 급속히 투입시킴에 따라 많은 혼란이 야기되어진 수행평가에 현장 적용에 대한 문제점 에 대한 연구가 많이 이루어지고 있다. 이들 연 구에서는 '정책의 강요로 인한 본질 왜곡', '수행 평가 적용 여건 미비', '교사의 평가 전문성 부 족', '교사의 부담' 등이 언급되고 있다(남명호, 2007; 서지영, 김명화, 김소영, 2010).

즉 한국에서의 수행평가에 관한 문제점으로 지 적되고 있는 것 중 수행평가가 효율적 실현가능 성의 고려됨이 없이 당위성에 의해 교육현장에 강요된 교육개혁 프로그램이란 부분이며 아직도 그에 대한 연구가 많이 이루어지고 있는 중이다.

나. 중국에서의 수행평가

중국 초, 중등학교 학교 교육에서 평가의 중요 성은 일찍이 1960년대부터 나타나기 시작되었다. 이후 중국 교육에 대한 발전은 문화 대혁명 동안 에 잠시 정체되었다가 문화 대혁명이후 다시 일 어나기 시작하였다. 1984년 5월 중국이 정식적으 로 국제에너지기구(IEA) 가입한 이후부터 중국의 교육발전은 급속도로 진행되었으며 중국의 교육 평가 영역 또한 빠른 속도로 발전하였다. 1991년
5 월 <의무교육법>, <교육법>, <교사법>등 일련의 제도와 법규를 나타나면서 중국에서 학생에 대한 수행평가가 전면적으로 시작되었다. 따라서 앞에 서 언급한 일련의 제도와 법규들은 수행평가에 대한 어느 정도에서 표준과 법적 근거가 되었다. 2001년 6월에는 새로운 교육법규인 <기초교육과 정 개혁>이 발표되었다. 이것은 중국 기초교육과 정이 일정부분 새로운 단계에 진입한 것으로 보 여 진다. 이에 따라 현재 중국의 교육에서 수행 평가는 새로운 교육과정이 실시되는데 있어 가장 중요한 부분을 차지한 것으로 볼 수 있다.

중국에서 수행평가에 관한 선행연구는 최근 많 이 이루어지고 있다. 그 중 曲娜(2009)는 중국의 무교육단계에서 수행평가의 문제 및 대책 연구를 통해 수행평가의 문제점에 대해 언급하였다. 이 연구에서 중국 내외에서 이루어진 수행평가 관련 연구 분석을 통해 중국의무교육단계에서 수행평 가 발생한 문제점을 해결 방법을 제시하고 있다.

중국에서 연구되어진 다른 연구를 보면 수행평 가의 장점으로서는 학생이 가지고 있는 발전 가 치를 한 번의 시험으로 따지지 않아도 된다는 점 을 꼽고 있다. 수행평가에서 가장 핵심적인 부분 은 학생들의 지식과 기능을 수시로 평가할 수 있 다는 점이다.(蔡永红,2002)

이러한 수행평가가 중국에서 잘 이루어지고 있 는지 파악하는 데에 관한 선행연구는 아직 잘 이 루어지고 있지 않다. 본 연구는 교사의 관심에 기초한 교육과정 실행 모형(CBAM: concerns -based adoption model)을 이용하여 교육 프로그 램에 대한 중국 교사 개인의 관심, 실행수준과 실행형태를 평가하는데 활용될 수 있는 진단도구 를 제공하며(Hall \& Hord, 1987), 이를 통하여 중국 수행평가의 현장 적용 실태를 파악하여 실 행주체인 교사에게 구체적인 지원 처방책을 마련 하여 중국 수행평가의 성공적인 정착과 운영에 도움을 주고자한다. 


\section{2. 관심도}

본 연구에서 관심(concern)이란 교사가 변화를 실행하는 프로그램 속에서 나타내는 것으로 교육 프로그램에 관해 교사가 가지는 나름대로의 감정 이나 생각과 같은 반응들을 의미한다.

교육 프로그램이 학교에 잘 정착되지 않는 데 에는 여러 가지 이유가 있을 수 있다. 교육과정 편제상의 문제, 교육과정 수준 문제, 국가 통제하 의 획일적인 관리 요인, 입시위주의 파행적인 운 영 문제 등이 있으나 무엇보다 중요한 요인은 교 육프로그램에 대한 현장 교사들의 관심과 실행이 다(김경자, 1993). 학교와 같은 조직체에서 변화 가 성공적으로 일어나기 위해서는 다방면한 접근 이 이루어져야 하는데, 교육프로그램이 학교에 보 급될 때, 교사들이 개정을 어떻게 받아들이고 수 행하는지를 연구하는 것은 아주 중요한 일이다.

이와 같은 교사들의 교육 효율성을 위한 연구 는 많이 이루어지고 있다. Fuller(1969)는 예비교 사들을 대상으로 한 교사 발달 단계 연구에서 예 비 교사들의 수업 상황을 관찰하고, 교사들의 교 육프로그램에 대한 관심의 발달 단계를 규명하였 다. Hall(1979)은 이를 확장하여 교사들이 어떻게 관심의 단계를 경험하는지를 보완하였고, 그 후 Hall(1979)은 텍사스대학교 교사교육연구소 (Research and Development for Teacher Education, Univ. of Texas at Austin)에서 최초 의 관심에 기초한 교육과정 실행모형(Concerns Based Adoption Model: CBAM)이라는 개념을 사용하였다.

$\mathrm{CBAM}$ 은 이러한 변화에 대한 몇 가지 가정을 중심으로 개발되었는데, $\operatorname{Darr}(1985)$ 은 CBAM의 가정이 크게 두 부분으로 나누어진다고 보았다 (최진영, 1996. 재인용). 가정 중 첫 번째 부분은 교사 개인이 이러한 변화에 대해 가지는 관심과 교육과정을 어떻게 실행하는지와 관련된 것이고, 두 번째 부분은 여기에 변화를 구상하고 기획하 고 추진하는 일을 담당하는 변화 촉진자(Change facilitator)가 변화과정에 있는 각 실행자마다 그 들이 필요로 하는 적절한 지원을 제공할 수 있다 는 것과 관련된 것이라 할 수 있다. 변화 촉진자 는 이 $\mathrm{CBAM}$ 도구를 활용하여 교육프로그램을 실행하는 주체자인 교사가 교육프로그램에 대하 여 어느 정도 관심을 갖고 실행하는 지에 대한 진단적 정보를 수집하여 정보에 따라 실행 주체 자인 개인에게 적절하고 유용한 지원을 할 수 있 게 된다. 그래서 교육프로그램의 실행 정도에 대 한 세 가지 진단평가 도구는 관심도(Stage of Concern: SoC), 실행수준(Level of Use: LoU)과 실행형태(Innovation Configuration: IC)가 있다. 본 연구와 관련이 있는 관심도에 대하여 살펴보 도록 하겠다.

$\mathrm{CBAM}$ 의 변화에 대한 몇 가지 가정을 중심으 로 개발되었는데 구체적으로 살펴보면 그 구체적 인 내용은 다음 <표 $1>$ 에 나와 있다.(김경자, 1993).

<표 1> 교육 프로그램에 대한 교사들의 관심 7 단계

\begin{tabular}{|c|c|c|}
\hline 관심 단계 & $\begin{array}{l}\text { 영역별 } \\
\text { 관심 } \\
\text { 단계 }\end{array}$ & 관심의 표현 \\
\hline 단계0. 무관심 & \multirow{3}{*}{ 자신 } & 무관심 \\
\hline 단계 1 . 정보적 & & 일반적인 정보에 관심 \\
\hline 단계2. 개인적 & & $\begin{array}{c}\text { 자신에게 미칠 영향에만 } \\
\text { 관심 }\end{array}$ \\
\hline 단계3. 운영적 & 업무 & $\begin{array}{l}\text { 효율성, 조직화, } \\
\text { 실행계획에 관심 }\end{array}$ \\
\hline 단계 4 . 결과적 & \multirow{3}{*}{ 결과 } & $\begin{array}{c}\text { 학생에게 미칠 영향에 } \\
\text { 관심 }\end{array}$ \\
\hline 단계5. 협동적 & & 동료들과 협력 \\
\hline $\begin{array}{r}\text { 단계 } 6 . \\
\text { 대안탐색 }\end{array}$ & & $\begin{array}{c}\text { 보편적인 이점의 탐색에 } \\
\text { 관심 }\end{array}$ \\
\hline
\end{tabular}

\section{3. 실행 수준}

교육 프로그램에 대한 교사의 관심도는 진단지 표로서 상당한 의미를 가지고 있다. CBAM은 교 육 프로그램의 진단을 통한 지원책을 개발하여 변화를 촉진하고자 하는 것이 목적이기에 앞에 
언급한 교육 프로그램에 대한 교사의 관심도 측 정치만으로 교육의 프로그램을 제대로 진단하는 것은 부족하다. 즉 실제로 교육현장에서 교육 프 로그램이 어떻게 실행되고 있는지에 대한 수준을 살펴볼 필요가 있다(Hord et al., 1987). 실행수준 은 교육 프로그램을 실행하는 교사의 행동에 대 한 기술을 의미하는데, $\mathrm{CBAM}$ 에서는 발달적 측 면에서 그것을 8단계로 구분하여 제시하고 있다 (Hall et al., 1977). 실행 수준은 교사가 교육과정 혁신에 관하여 실제로 무엇을 행하고 있는가를 조작적으로 규명하려는 것으로 발달적 성격을 지 니며, 그 구체적인 내용은 <표 2>과 같다.

$<$ 표 2> 교육과정 혁신에 대한 실행 수준의 8 단계

\begin{tabular}{c|c|c}
\hline \multicolumn{2}{c|}{ 실행 수준 } & 내용 \\
\hline \hline \multirow{2}{*}{ 실 } & 0. 비실행 & 비실행 \\
\cline { 2 - 3 } 행 & 1. 오리엔테이션 & 정보 습득 및 탐색 \\
\cline { 2 - 3 } & 2. 준비 & 실행 준비 \\
\hline \multirow{2}{*}{ 비 } & 3. 기계적 사용 & 단기적 실행 \\
\cline { 2 - 3 } 실 & 4. 일상화 & 안정화 \\
\cline { 2 - 3 } 행 & 5. 정교화 & 혁신 실행 변화 \\
\cline { 2 - 3 } & 6. 통합화 & 동료교사와 협력 \\
\cline { 2 - 3 } & 7. 갱생 & 대안 탐색 \\
\hline
\end{tabular}

<표 2>에서 보면, 실행수준은 크게 프로그램을 실행하지 않는 수준(비활용, 오리엔테이션, 준비) 과 실행하는 수준(기계적 사용, 일상화, 정교화, 통합화, 갱생)으로 나눌 수 있다.

$\mathrm{CBAM}$ 을 활용한 수행평가에 대한 교사의 관 심과 실행수준을 분석한 선행연구로는 초등학교 과학교과에 관한 장수미 등(2002)의 연구와 중학 교 기술·가정 교과에 관한 정미정(2004)의 연구가 있다.

\section{III. 연구 방법}

\section{1. 연구 대상}

본 연구는 중국 중학교 교사들의 수행평가에 관한 관심도와 실행수준을 알아보기 위하여 중국
에서 현재 가장 교육정책 변화가 빠르게 일어나 는 수도 북경시에 있는 중학교 5 개를 단순무선 표집하였다. 여기서 각 학교별로 중학교 교사 25 명씩 비례할당표집을 실시 총 125 명 중학교 교사 들을 대상으로 설문조사를 하였다. 배부된 설문 지 125 개 중 교육청별로 중등교사 25명씩 비비례 할당표집을 실시하였다. 설문조사 결과, 배부된 설문지 120 부 중 102 부가 회수되어 $86.7 \%$ 의 회수 율을 보였다. 회수된 설문지에는 무응답 문항이 있는 설문은 없었다. 회수된 설문지 102 부의 설 문지를 최종 연구 자료로 삼았다. 분석된 자료의 변인별 기술통계는 <표 3>과 같다.

<표 3> 분석된 자료의 개인 배경 변인별 기술 통계 $(\mathrm{N}=102)$

\begin{tabular}{c|c|c}
\hline 개인 배경 병인 & 구 분 & $\mathrm{n}$ \\
\hline \hline \multirow{2}{*}{ 성별 } & 남자 & 41 \\
\cline { 2 - 3 } & 여자 & 61 \\
\hline \multirow{3}{*}{ 학력 } & 전문대학 & 9 \\
\cline { 2 - 3 } & 대학교 & 72 \\
\cline { 2 - 3 } & 대학원 & 21 \\
\hline \multirow{2}{*}{ 경력 } & $1-9$ 년 & 46 \\
\cline { 2 - 3 } & $10-19$ 년 & 45 \\
\cline { 2 - 3 } & 20년 이상 & 11 \\
\hline
\end{tabular}

\section{2. 연구 도구}

본 연구에서는 관심도에 대한 3 가지 진단도구 중에서 도구의 타당도와 신뢰도가 검증되어 가장 객관성이 보장되는 관심단계 질문지법(George, Hall, \& Stiegelbater, 2006)을 활용하여 설문지를 수정하여 사용하였다. 질문지의 문항은 수행평가 에 대한 관심과 일치하는 정도에 따라 0 점부터 4 점으로 표시하였다.

본 설문지에서 원안인 관심의 7단계(Hall et al., 1977)중 0단계의 무관심과 7단계의 대안탐색 단계는 내용타당도 검증에서 수행평가가 정책적 으로 현재 실행 중인 프로그램이기에 이 단계들 에 대한 설문은 적절치 않다고 판단되어 삭제하 였다. 본 설문지의 각 단계별 Cronbach $\alpha$ 의 범 위는 .63 에서 .68 이며, 전체 문항의 신뢰도는 .89 
이다.

수행평가에 대한 중학교 교사들의 실행수준을 진단하는 설문지를 만들기 위하여 Hall 등(2006) 이 제안한 8단계의 실행수준 참고하였다. 전체 문항은 1 개의 문항으로 하고 각 실행수준을 반응 지로 하여 이들을 수행평가와 관련되게 자세하게 표현하였다. 교사들은 이 중 본인과 일치하는 1 개만 응답하도록 하였다.

본 연구는 8 개 수준 중에서 비실행 수준과 갱 생 단계을 삭제하고 6 개 수준을 이용하여 설문지 를 수정하였다(Hall et al., 2006). 0단계의 문항인 비실행 수준과 7단계인 갱생 단계를 삭제한 이유 는 중국에서 현재 수행평가가 정책적으로 실행 중인 프로그램이고 이 설문에 포함하는 것은 적 절치 않다고 판단하였기 때문이다. 본 설문지의 문항은 <표 $4>$ 와 같다.

\section{<표 4> 관심 단계별과 실행 수준 문항}

\begin{tabular}{c|c|c}
\hline 변 인 & 문항 번호 & 문항 수 \\
\hline \hline $\begin{array}{c}\text { 1단계 } \\
\text { (정보적 관심) }\end{array}$ & $5,12,13,22,30$ & 5 \\
\hline $\begin{array}{c}\text { 2단계 } \\
\text { (개인적 관심) }\end{array}$ & $6,11,15,24,28$ & 5 \\
\hline $\begin{array}{c}3 \text { 단계 } \\
\text { (운영적 관심) }\end{array}$ & $3,7,14,21,29$ & 5 \\
\hline $\begin{array}{c}4 \text { 단계 } \\
\text { (결과적 관심) }\end{array}$ & $1,10,17,20,27$ & 5 \\
\hline $\begin{array}{c}5 \text { 단계 } \\
\text { (협력적 관심) }\end{array}$ & $4,9,16,23,25$ & 5 \\
\hline 실행 수준 & 31 & 1 \\
\hline & 전체 & 26 \\
\hline
\end{tabular}

\section{3. 자료처리 방법}

본 연구에서 수집된 자료의 처리를 위해 SPSS/WIN 18.0 프로그램을 활용하였고 이 중 빈도분석, 다변량 변량분석, 상관분석을 이용하서 자료를 분석하였다.

가. 관심도

중국 중학교 교사들의 수행평가에 대한 개인별
관심도를 파악하기 위하여 각 단계별 관심도의 원점수를 표준점수로 환산하여, 표준점수가 가장 높은 관심 단계를 수행평가에 대한 개별 교사의 관심 단계로 간주하여 빈도분석을 실시하였다. 또 교사 개인 성별, 학력, 경력에 따른 관심도의 차이가 있는지를 살펴보기 위하여 다변량 변량분 석(MANOVA)을 실시하였다.

나. 실행 수준 관계 분석

수행평가에 대한 중학교 교사들의 실행수준을 분석하기 위하여 빈도분석을 실시하였고, 개별관 심 단계와 실행수준의 상관을 밝히기 위하여 상 관분석의 적률상관 분석을 실시하였다.

\section{IV. 연구 결과}

\section{1. 수행평가에 대한 중국 중학교 교사들의 개인별 관심도}

현행 수행평가에 관한 중국 북경시 중학교 교 사들의 개별적인 관심도에 대한 기술통계 분석 결과는 <표 $5>$ 와 같다.

<표 5> 북경시 교사들의 수행평가 관심도 $(\mathrm{N}=102)$

\begin{tabular}{cccccc}
\hline $\begin{array}{c}\text { 영역단 } \\
\text { 계 }\end{array}$ & \multicolumn{2}{c}{ 자신 } & 업무 & \multicolumn{2}{c}{ 결과) } \\
(개인) & (운영) & 4 (결과) & (협력) \\
\hline \hline 빈도 & 29 & 19 & 18 & 16 & 20 \\
$\%$ & 28.4 & 18.6 & 17.6 & 15.7 & 19.6 \\
\hline
\end{tabular}

교사들의 개별 관심도는 1 단계(정보)가 가장 높은 빈도를 보였고, 그 다음에 5단계(협력), 2단 계(개인), 3 단계(운영), 마지막으로 4단계(결과)가 가장 낮은 빈도를 보였다. <표 5>를 보면 정보적 관심의 단계가 가장 높고, 결과적 관심도가 다른 단계보다 낮게 나타났다. 정보적 관심이 높다는 것은 북경시 교사들이 수행평가에 대한 일반적 정보에 대해 상대적으로 관심이 높다고 할 수 있 을 것이다. 특히 4단계(결과)를 주목할 필요가 있 다. 이것은 중국의 중학교 교사들이 수행평가가 
학생들에게 미칠 영향에 관심이 부족하다는 것으 로 볼 수 있다.

\section{2. 수행평가에 관한 중국 중학교 교사들의 개인 배경별 관심도}

중학교 교사들의 개인 배경에 따른 수행평가에 관한 관심도 차이를 분석하기 위하여 성별, 학력
별, 경력별로 다변량 분산분석을 실시하였고, 분 석결과는 다음과 같다.

가. 성별에 따른 중국 중학교 교사들의 관심도 성별에 따른 수행평가에 관한 중국 중학교 교 사들의 관심도에 통계적 유의미한 차이가 있는지 알아보기 위해 다변량 분산분석을 실시한 결과는 <표 6>과 같다.

<표 6> 성별에 따른 중학교 교사들의 관심도의 기초통계량

$(\mathrm{N}=102)$

\begin{tabular}{|c|c|c|c|c|c|c|c|}
\hline \multirow{2}{*}{ 구분 } & \multicolumn{4}{|c|}{ 성별 } & \multirow{3}{*}{ Wilks' $\Lambda$} & \multirow{3}{*}{$d f$} & \multirow{3}{*}{$F$} \\
\hline & \multicolumn{2}{|c|}{ 남자(n=41) } & \multicolumn{2}{|c|}{ 여자 $(n=61)$} & & & \\
\hline 종속 변인 & $\mathrm{M}$ & $\mathrm{SD}$ & $\mathrm{M}$ & $\mathrm{SD}$ & & & \\
\hline 1단계(정보) & 15.17 & 2.85 & 14.84 & 2.70 & \multirow{5}{*}{.95} & $1 / 100$ & .36 \\
\hline 2단계 (개인) & 15.98 & 2.82 & 14.84 & 3.13 & & $1 / 100$ & 3.53 \\
\hline 3단계 (운영) & 14.44 & 2.95 & 14.43 & 2.82 & & $1 / 100$ & .00 \\
\hline 4단계 (결과) & 16.61 & 2.33 & 16.10 & 2.82 & & $1 / 100$ & .93 \\
\hline 5단계 (협력) & 15.68 & 2.81 & 14.93 & 2.65 & & $1 / 100$ & 1.87 \\
\hline
\end{tabular}

수행평가에 대하여 남자 교사들은 4 단계(결과)의 관심도 평균이 가장 높았고, 3 단계(운영)가 가장 낮았다. 여자 교사들 역시 4 단계(결과)의 관심도 평균이 가장 높았고, 3단계(운영)가 가장 낮았다. 설문지에 응답한 41 명 남자 교사들의 관심도와 61 명 여자 교사들의 관심도에 대한 단계별 오름 차순 평균(표준편차)들은 아래 <표 6>와 같다. 각 성별에 따른 관심도 평균의 경향은 비슷하다 는 것을 알 수 있다. 하지만 남자 교사들은 2 단 계(개인) 요인에서 여자교사들에 비해 다소 높게 나타나는 것으로 보여 진다.

<표 6>에 나온 것과 같이 수행평가에 관한 중학교 교사들의 성별에 따른 관심도의 평균에 차이가 있는 것으로 보아, 이러한 것들이 통계적 유의미한 차이가 있는지 다변량 분산분석을 통해 살펴보았다. 다변량 분산분석은 수행평가에 대한 성별에 따른 중학교 교사들의 관심도의 차이 검 증을 위하여 성별을 독립변인으로, 관심도의 각 단계를 종속변인으로 설정하여 분석하였다. 이 결과 각각의 종속변수별로 성별에 따른 관심도
차이는 1 단계(정보), 3 단계(운영), 4 단계(결과), 5 단계(협력)에서 유의미한 차이가 없었다.

나. 학력에 따른 중학교 교사들의 관심도 수행평가에 대한 학력별 중학교 교사들의 관심 도의 분석결과는 <표 7>과 같다. 전문대학의 경 우 4 단계(결과)의 관심도 평균이 가장 높았고, 3 단계(운영)가 가장 낮았다. 대학교는 4 단계(결과) 의 관심도 평균이 가장 높았고, 1 단계(정보)가 가 장 낮았다. 대학원은 4 단계(결과)의 관심도 평균 이 가장 높았고, 3 단계(운영)가 가장 낮았다. 설 문지에 응답한 각각의 다른 학력 교사들의 관심 도에 대한 단계별 오름차순 평균(표준편차)들은 <표 7>과 같다.

이러한 것들이 통계적 유의미한 차이가 있는지 다변량 분산분석을 통해 살펴보았다. 여기서 수 행평가에 대한 학력별 중학교 교사들의 관심도의 차이 검증을 위하여 교사의 학력을 독립변인으로 관심도의 각 단계를 종속변인으로 설정하여 분석 하였다. 
이서우·김태현 · 김석우

<표 7> 학력에 따른 중학교 교사들의 관심도의 기초통계량

$(\mathrm{N}=102)$

\begin{tabular}{|c|c|c|c|c|c|c|c|c|c|}
\hline \multirow{2}{*}{ 구분 } & \multicolumn{6}{|c|}{ 학력 } & \multirow{3}{*}{ Wilks' $\Lambda$} & \multirow{3}{*}{$d f$} & \multirow{3}{*}{$F$} \\
\hline & \multicolumn{2}{|c|}{ 전문대학 $(n=9$} & \multicolumn{2}{|c|}{ 대학교 $(\mathrm{n}=72)$} & \multicolumn{2}{|c|}{ 대학원 $(n=21)$} & & & \\
\hline 종속 변인 & $\mathrm{M}$ & $\mathrm{SD}$ & $\mathrm{M}$ & $\mathrm{SD}$ & $\mathrm{M}$ & $\mathrm{SD}$ & & & \\
\hline 1단계 (정보) & 15.11 & 1.97 & 14.86 & 2.94 & 15.29 & 2.43 & \multirow{5}{*}{.94} & $2 / 99$ & .20 \\
\hline 2단계 (개인) & 15.56 & 1.94 & 15.26 & 3.28 & 15.29 & 2.67 & & $2 / 99$ & .04 \\
\hline 3단계 (운영) & 13.67 & 2.78 & 14.96 & 2.88 & 13.86 & 2.80 & & $2 / 99$ & 1.05 \\
\hline 4단계 (결과) & 16.56 & 2.19 & 16.26 & 2.68 & 16.33 & 2.75 & & $2 / 99$ & .05 \\
\hline 5단계 (협력) & 15.11 & 3.44 & 15.29 & 2.72 & 15.10 & 2.53 & & $2 / 99$ & .05 \\
\hline
\end{tabular}

또한 각각의 학력에 따른 관심도 차이는 모든 단계에서 유의미한 차이가 없었다.

다. 경력에 따른 중국 중학교 교사들의 관심도

수행평가에 대한 경력별 중국 중학교 교사들의 관심도의 분석결과는 <표 8>과 같다. 1-9년 경력, 10-19년 경력을 가진 교사들의 관심도 평균은 4 단계(결과)가장 높았고, 3 단계(운영)가 가장 낮았
다. 10-19년 경력은 4단계(결과)의 관심도 평균이 가장 높았고, 3단계(운영)가 가장 낮았다. 20년 이상 경력은 4 단계(결과)의 관심도 평균이 가장 높았고, 3 단계(운영)가 가장 낮았다. 모든 경력별 로 교사들이 프로그램의 실행이 학생들에게 어떠 한 영향을 미치는지 많은 관심을 보이는 것으로 나타났다.

<표 8> 경력에 따른 중학교 교사들의 관심도의 기초통계량

$(\mathrm{N}=102)$

\begin{tabular}{|c|c|c|c|c|c|c|c|c|c|}
\hline \multirow{2}{*}{ 구분 } & \multicolumn{6}{|c|}{ 경력 } & \multirow{3}{*}{$\begin{array}{c}\text { Wilks' } \\
\Lambda\end{array}$} & \multirow{3}{*}{$d f$} & \multirow{3}{*}{$F$} \\
\hline & \multicolumn{2}{|c|}{$0-9$ 년 $(n=46)$} & \multicolumn{2}{|c|}{$10-19$ 년 $(n=45)$} & \multicolumn{2}{|c|}{20 년이상 $(n=11)$} & & & \\
\hline 종속 변인 & $\mathrm{M}$ & $\mathrm{SD}$ & $\mathrm{M}$ & $\mathrm{SD}$ & $\mathrm{M}$ & $\mathrm{SD}$ & & & \\
\hline 1단계(정보) & 14.57 & 2.54 & 15.31 & 2.88 & 15.27 & 3.07 & & $2 / 99$ & .91 \\
\hline 2단계 (개인) & 15.26 & 2.74 & 15.31 & 3.53 & 15.36 & 2.20 & & $2 / 99$ & .01 \\
\hline 3단계 (운영) & 14.17 & 2.57 & 14.71 & 3.01 & 14.36 & 3.53 & .96 & $2 / 99$ & .40 \\
\hline 4단계 (결과) & 16.22 & 2.70 & 16.22 & 2.71 & 17.00 & 2.05 & & $2 / 99$ & .43 \\
\hline 5단계 (협력) & 15.00 & 2.65 & 15.38 & 2.85 & 15.64 & 2.66 & & $2 / 99$ & .35 \\
\hline
\end{tabular}

<표 8>에서 보면 수행평가에 관한 경력별 중 학교 교사들의 관심도의 평균에 차이가 있는 것 으로 보이지만, 이러한 것들이 유의미한 차이인 지 다변량 분산분석을 통해 살펴보았다. 수행평 가에 대한 경력별 중학교 교사들의 관심도의 차 이 검증을 위하여 경력을 독립변인으로 관심도의 각 단계를 종속변인으로 설정하여 분석하였다.

또한 각 각의 종속변수별로 경력에 따른 관심도 차이는 모든 단계에서 유의미한 차이가 없었다.

\section{3. 중국 중학교 교사들의 수행평가에 관한 실행 수준}

<표 9>에서 보면 수행평가에 대한 중학교 교 사들은 4 단계(일상화)에 가장 높은 빈도를 나타 냈다. 그 다음에 3 단계(기계적 실행)에 아주 낮은 빈도를 나타냈다. 5단계(정교화)와 6단계(통합화) 에 비슷한 빈도를 볼 수 있다.

<표 9> 수행평가에 관한 중학교 교사들의 실행 수준

$(\mathrm{N}=102)$

\begin{tabular}{cccccc}
\hline \multirow{2}{*}{ 수준 } & $\begin{array}{c}2 . \\
\text { 준비 }\end{array}$ & $\begin{array}{c}\text { 3. 기계적 } \\
\text { 실행 }\end{array}$ & $\begin{array}{c}4 . \\
\text { 일상화 }\end{array}$ & $\begin{array}{c}5 . \\
\text { 정교화 }\end{array}$ & $\begin{array}{c}6 . \\
\text { 통합화 }\end{array}$ \\
\hline \hline 교사 수 & 14 & 4 & 39 & 25 & 20 \\
\hline$\%$ & 13.7 & 3.9 & 38.2 & 24.5 & 19.6 \\
\hline
\end{tabular}


결과를 보면 중국에서도 수행평가의 실행이 안 정화되어 학교 현장에서 잘 실행되고 있다고 볼 수 있다.

\section{4. 중학교 교사들의 수행평가에 관한 개별 관심도와 실행수준의 관계}

수행평가에 관한 중학교 교사들의 개별 관심도 와 실행수준간의 관계를 알아보기 위하여 Pearson 의 적률상관을 실행해 본 결과, <표 $10>$ 에서 나 타난 것과 같이 중국 중학교 교사들의 개별 관심 도와 실행수준 간 상관관계가 나타나지 않았다.

<표 10> Pearson 적률 상관 분석 결과

\begin{tabular}{ccc}
\hline & 상관계수 & 유의확률 \\
\hline \hline $\begin{array}{l}\text { 관심도와 } \\
\text { 실행수준 }\end{array}$ & .072 & .472 \\
\hline$p<.01$ & & \\
\hline
\end{tabular}

\section{$\mathrm{V}$. 논의 및 결론}

본 연구의 목적은 중국 중학교 교사들의 수행 평가에 관한 관심도와 실행 수준을 진단하고 수 행평가에 대한 현장적용에 대한 문제점을 개선할 실질적이고 효과적 방안을 만들기 위해 $\mathrm{CBAM}$ 을 활용하여 수행평가에 관한 중학교 교사들의 관심 도와 실행 수준을 진단하고 이들의 관계를 살펴 보았다.

본 연구의 결과를 연구목적 및 선행연구와 관 련지어 논의하고, 그 시사점을 제안하면 다음과 같다.

첫째, 중국 중학교 교사들의 수행평가에 관한 개별적인 관심도를 보며 1 단계인 정보적 관심이 가장 많은 빈도를 차지하였고, 5 단계 협력적과 2 단계 개인적 관심도 많은 빈도를 보였으나, 4 단 계 결과적 관심이 가장 낮은 빈도를 나타내었다. 즉 정보적 관심은 교사들이 새로운 교육 프로그 램에 관해 좀 더 알고 싶어 하는 것을 의미한다. 이는 중국 중학교 교사들이 실제 수행평가를 활
용하는 측면에서 현재 수행평가가 중국 중학교 교육현장에서 수행은 되고 있으나 수행평가에 대 한 구체적인 정보가 교사들에게 제대로 전달이 되지 않음을 암시하고 있다고 볼 수 있다. 위의 연구결과는 한국 중학교 교사들의 수행평가에 관 한 관심도와 실행수준 분석연구를 한 이대용 (2011)의 결과와 차이가 있다. 한국의 중학교 교 사들의 개별 관심도 분석에 있어 1 단계 정보적 관심이 적은 빈도를 차지하였다. 이는 수행평가 가 중국에서 이루어지고 있음에도 교사들이 수행 평가에 대한 업무에 있어 능숙하고 잘 활용하는 것에 대한 정보의 부족이 아직은 있다고 볼 수 있을 것이다.

둘째, 중국 중학교 교사들의 수행평가에 관한 교사들의 성별, 학력별, 그리고 경력별에 따라서 관심도에는 차이가 없었다. 위의 연구결과는 한 국 중학교 교사들의 수행평가에 관한 관심도와 실행수준 분석연구를 한 이대용(2011)의 결과와 동일하다. 이대용(2011)의 연구결과를 통해 본 연 구의 결과를 고찰한다면 중국에서 수행평가가 정 부시책으로 10 여년 가까이 시행된 프로그램이기 에 개인배경별에 대한 관심도에 차이가 발생하지 않았다고 보여 진다.

셋째, 중국 중학교 교사들의 수행평가에 관한 실행 수준에 대한 결과를 보면 수행평가의 실행 이 안정화되어 실행에서 변화가 거의 없다고 나 타났다. 일상화 수준이 가장 높게 나온 것으로 살펴볼 때 중국의 교육현장에서 수행평가는 중국 정부시책에 의해 강제적으로 시행되어진 부분이 라 중국의 중학교 현장에서 어느 정도 안정화 되 어 실행되고 있다고 볼 수 있다.

넷째, 중국 중학교 교사들의 수행평가에 관한 개별 관심도와 실행수준의 관계를 살펴본 결과를 개별 관심도와 실행수준 간에는 부적 상관관계가 나타났다. 이는 이대용(2011)의 연구에서 나타난 한국 중학교 교사들의 수행평가에 대한 관심도와 실행수준에는 낮은 정적상관 관계가 있다는 결과 와는 다르게 나타난 것이다. 위의 연구결과는 여 
성아(2011)의 연구에서도 나타난 바와 같이 교사 내적 요인에 있어 교사의 교육과정 전반에 대한 관심의 부족을 들 수 있다. 대체로 중국의 교육 현장에서 교사들은 교육과정이 아니라 교과서와 지도서에 의존한 교육활동이 많이 이루어지고 있 다. 이러한 교육방식으로 수행평가가 이루어 질 수 있는 교육과정에 대한 관심이 드물다고 할 수 있다.

이러한 결과를 바탕으로 다음과 같이 결론을 제시하고자 한다.

첫째, 수행평가에 대한 중국 중학교 교사들의 관심 수준이 수행평가를 실행할 때 망설이거나 아니면 큰 관심을 보이지 않는 경우가 아니라, 실제 수행평가를 실행하면서 교사들이 수행평가 에 대한 일반적인 정보와 자신에게 미칠 영향에 대해 자신에게 얼마 영향을 주는지를 잘 알아보 고 나서 실행할 때 학생들에게 어떤 효과를 보인 다는 생각을 가지고 있다는 것을 알 수 있다. 또 정보적 관심이 상당히 많은 빈도를 차지한다고 보았을 때 중국 교육당국에서 수행평가 실행에 관한 논의에 교사를 참여시키고 교사가 적절히 사용할 수 있도록 정보를 충분히 제공해 주어야 한다. 이러한 지원이 제대로 이루어질 때 중국 중학교 교사들의 수행평가 활용이 제대로 이루어 질 수 있을 것이다. 수행평가에 대한 정보 잘 알 고 실행할 때 더 잘 실행할 수 있다는 것을 의미 한다고 할 수 있을 것이다.

둘째, 중국 중학교 교사들의 수행평가에 관한 개별 관심도와 실행수준의 관계를 살펴본 결과를 개별 관심도와 실행수준간의 상관이 없다고 나타 났다. 이러한 점을 개선하기 위해서 중국 교육당 국에서 중국 교사들의 기계적인 활용수준에 머물 러 있는 수행평가를 보다 높은 실행수준으로 옮 겨갈 수 있도록 여러 활동들이 마련되어져야 한 다. 이를 위해 중국 교육당국에서 교사들이 가지 고 있는 문제를 중심으로 연수, 상담, 혹은 동료교 사와의 상호 지원 체제 등을 마련해 주며 교사 연 수의 기회제공을 확대하여야 하며 교사들이 활용
할 수 있는 수행평가 관련자료 개발이 필요하다.

마지막으로 본 연구는 다음과 같은 제한점을 갖고 있다.

첫째, 본 연구는 중국 북경시 관내에 소재하는 중학교 교사를 대상으로 실시한 것이므로 연구결 과를 중국 모든 관내의 학교에 적용하는 데는 무 리가 따른다.

둘째, 본 연구는 중국 수행평가에 대한 중학교 교사의 관심수준을 알아보기 위한 방법으로 설문 조사에 한정되어 있고 표집의 수도 102명으로 한 정되어 있다. 또 본 연구에서 사용되어진 실행수 준 문항은 한 문항뿐 이다. 관찰이나 인터뷰 등 을 통한 폭넓은 자료수집에 한계가 있다.

\section{참고 문헌}

김경자 역(1993). 교육과정 혁신: 관심에 기초한 교육과정 실행 모형(CBAM), 서울: 교육과학사. 김석우·이대용·강영이(2011). 중학교 교사들의 수 행평가에 관한 관심도와 실행수준분석, 교육평 가연구, 24(1), 31 50.

김은영(1994). 초등교사들의 자연과 교육과정에 대한 관심도, 이화여자대학교 석사학위 논문.

김재헌(1996). 체육교육과정에 대한 교사의 관심 도와 활용도 연구, 서울대학교 석사학위 논문.

김혜나(2011). CBAM의 실행 측정 도구의 발전과 정과 쟁점 분석, 부산대학교 석사학위 논문.

박주상(1994). 교육과정에 대한 교사들의 관심도와 활용도 연구, 한국교원대학교 석사학위 논문.

여성아(2011). 초등과학과 자유탐구 영역에 대한 교사의 관심분석, 부산대학교 석사학위 논문.

장수미·김재영(2002). 교사의 관심도에 기초한 초등 과학과 수행평가의 실태 분석, 초등과학 교육, 21(2),227-240.

정미정(2004). 기술·가정과 수행평가에 대한 중학 교 교사들의 관심도와 실행실태 조사, 한국교 원대학교 석사학위 논문

최진영(1996). 교육과정에 대한 교사들의 관심도, 실행형태, 및 실행수준의 관계, 이화여자대학교 석사학위논문.

蔡永紅(2011). 對敎師績效評估研究的回顧与反思[J], 高等師范敎育犐究, (3): 73-76. 
察永紅(2002)．敎師評价研究的緣起，問題及發展趨 勢[J], 北京師范大學學報, (1).

蔡永紅，林崇德(2005)．教師績效評价的理論与實踐 [J]. 教師教育䂰究, 27(1).

陳玉琨(2006)．教育評价學 $[\mathrm{M}]$ ，北京：人民敎育出 版社, 98 .

葛輝(2009). 中國大陸和台湾兩地中小學敉師評价指 標体系比較研究. 沈陽師范大學, 碩士學位論文.

姜紅(2005). 績效評估在敎師職業發展中的應用[J]， 教育探索, (4): 114 .

曲娜(2009). 我國義務敉育階段教師績效評价研究, 東北師范大學，碩士學位論文.

王敏(2010)．我國高校教師績效評价的問題及對策趼 究, 蘭州大學, 碩士學位論文.

吳淸山 等(2002). 教師績效責任研究[M], 台北：高 等敎育出版文化事業有限公司出版, 53.

楊華(2011). 我國呚師評价方法存在的問題探析及解 決對策[J]，遼宁師范大學學報，(5).

張洁(2005). 少前我國㸚師資格制度存在的問題[J]， 中國教師，(11), 55 56.

張其志(2006). 呚師評价的矛盾与分析[J]，教育研究 与實驗, (4): 30 31.

周朝森(1992). 敎育評价理論的新探索[J], 教育研究, (2).

Fullan, M., \& Pomfret, A.(1977). Research on curriculum and instruction implementation, Review of Educational Research, 47(1), 335 397.

Hall, G. E., Wallace, R. C., \& Dossett, W. A. (1973). A developmental conceptualization of the adoption process within educational institutions, Austin, TX: Research and Development Center for Teacher Education, the University of Texas at Austin.

Hall, G. E., George, A. A., \& Rutherford, W. L. (1977). Measuring stages of concern about the innovation A mannual for use of the soc questionnarire (Report No. Tm 006 654). Austin: Texas Univ, (ERIC Document Reproduction Service No. ED 147 342).

Hall, G. E., \& Hord, S. M.(2006). Implementing Change: Patterns, Principles, and Potholes(2th
Ed), Boston: Allyn and Bacon.

Hall, G. E. (2010). Technology's Achilles Heel: Achieving High-Quality Implementation. Journal of Research on Technology in Ecucation, 42(3), 231 253.

Heinecke, W., Blasi, L., \& Skerker, S.(2000). The process of an evaluation in progress. Measuring the impact of teaching with technology: Comprehensive Interdisciplinary Performance Assessment, Paper presented at he Secretary's Conference on Educational technology, 2000: Measuring Impacts and Shaping the Future. Alexandria, VA, September 11 12.

Hord, S. M., Rutherford, W. L., Hulling-Austin, L \& Hall, G. E.(1987). Taking Charge of Change, Alexanderia, VA: Association for Supervision and Curriculum Development.

Reynolds, C. R., Livingston, R. B., \& Willson, V.(2006). Measurement and assessment in education, New Jersey: Pearson Education.

Stiggins, R. (1994). Student-Centerd Classroom Assessment, New York: Macmillan.

Stiggins, R. J.(1995). Assessment literacy for 21st century, Phi Delta Kappan, 77, 238 245.

Tunks, J. \& Weller, K.(2009). Changing practice, changing minds, from arithmetical to algebraic thinking: an application of the concerns-based adoption model (CBAM), Educational Studies in Mathematics, vol. 72, no. 2, 161 183.

Vandenberghe, R.(1986). Studying Change in Primary and Secondary Schools in Belgium and the Netherlands, Paper presented at the Annual Meeting of the American Educational Research Association, Montreal, Quebec, Canada.

- 논문접수일 : 2012년 10월 29일

- 심사완료일 : 1차 - 2012년 11월 28일 2차 - 2013년 01월 11일

- 게재확정일 : 2013년 01월 16일 